\title{
Nutritional evaluation of herbaceous peony (Paeonia lactiflora Pall.) petals
}

\author{
Weixing Li ${ }^{1,3}$, Shunbo Yang ${ }^{1}$, Hui Cui', Yanmin Hua ${ }^{1}$, Jun Tao ${ }^{1,2}$, Chunhua Zhou ${ }^{1,2 *}$ \\ ${ }^{1}$ College of Horticulture and Plant Protection, Yangzhou University, Jiangsu Key Laboratory of Crop Genetics and Physiology, Yangzhou \\ 225009, China, '2Joint International Research Laboratory of Agriculture \& Agri-Product Safety, Yangzhou University, Yangzhou, 225009, China, \\ ${ }^{3}$ XiZang Agriculture and Animal Husbandry College, Linzhi, 860000, China
}

\section{A B S T R A C T}

\begin{abstract}
Herbaceous peony (Paeonia lactiflora Pall.) is a kind of plant with ornamental, edible and medicinal values, and few studies were concerned to edible aspect of herbaceous peony petals. The aim of this research is to establish edible quality evaluation system of herbaceous peony flowers. Petals of 46 P. lactiflora cultivars at full bloom period were used to determine the content of soluble sugar, organic acid, protein, Vc (Vitamin C), total phenolics, total flavonoids, mineral elements and SOD (superoxide dismutase) activity and screen out evaluation index for edible herbaceous peony. The results showed that flower petals of herbaceous peony contained lots of nutrients and the contents varied with different cultivars. The soluble sugar content was 66.55-177.28 mg/g FW, organic acid 2.19-6.90 mg/g FW, soluble protein 6.53-121.56 mg/g FW, Vc 9.77-30.24 mg/100 g FW, total phenolics 9.41-33.01 mg/g DW, total flavonoids 3.50-17.56 mg/g DW, SOD activity $305.62-520.42 \mathrm{U} / \mathrm{g} \mathrm{FW}$, total amino acids 6.43-11.99 g/100 g DW. The average content of $\mathrm{Na}, \mathrm{Mg}, \mathrm{K}, \mathrm{Ca}, \mathrm{Mn}, \mathrm{Fe}, \mathrm{Ni}, \mathrm{Zn}, \mathrm{Mo}, \mathrm{Cr}$ were $55.88 \pm 14.90 \mu \mathrm{g} / \mathrm{g}$ DW, $1218.22 \pm 349.60 \mu \mathrm{g} / \mathrm{g} \mathrm{DW}, 11252.23 \pm 2477.54 \mu \mathrm{g} / \mathrm{g}$ DW, $1975.40 \pm 706.58 \mu \mathrm{g} / \mathrm{g}$ DW, $8.30 \pm 6.55 \mu \mathrm{g} / \mathrm{g}$ DW, $103.56 \pm 182.72 \mu \mathrm{g} / \mathrm{g}$ DW, $10.73 \pm 37.94 \mu \mathrm{g} / \mathrm{g} \mathrm{DW}, 22.80 \pm 16.68 \mu \mathrm{g} / \mathrm{g} \mathrm{DW}, 1.84 \pm 5.89 \mu \mathrm{g} / \mathrm{g} \mathrm{DW}$ and $17.36 \pm 44.89 \mu \mathrm{g} / \mathrm{g} \mathrm{DW}$, respectively. Based on principal component analysis and cluster analysis, we found 'Dielian Qihua', 'Zhushapan', 'Xueyuan Honghua', 'Wulong Jisheng', 'Honglou', 'Bingshan', 'Hongyan Yushuang', 'Zituo Ronghua', 'Zifengyu', 'Fenlou Dianchun' had better edible quality. The results will provide some information for the comprehensive utilization of herbaceous peony petals and the breeding of edible herbaceous peony cultivars.
\end{abstract}

Keywords: Bioactive compound; Flower; Nutritional component; Paeonia lactiflora

\section{INTRODUCTION}

Edible flowers contribute to the increase of aesthetic appearance of food, they are used during the cooking preparation, but more often they are mentioned in connection with numerous nutritional and bioactive phytochemicals which contribute to their health benefits, and consumption of edible flowers has increased significantly in recent years (Mlcek and Rop, 2011; Xiong et al., 2014; Lu et al., 2016). The renewed interest in cooking and garnishing with flowers has also prompted extensive researches in the nutritional value of edible flowers (Cunningham, 2015). Edible flowers are rich in sugar, organic acid, protein, amino acid, mineral element, flavonoids, polyphenols, anthocyanins, carotenoids, fibers, volatiles and so on (Sotelo et al., 2007; Matthaus and Ozcan, 2011; Rop et al., 2012; Chen et al., 2015; Bayram et al., 2015; Benvenuti et al., 2016; Feng et al., 2016; Grzeszczuk et al., 2016), some of which are known to have biological activities and high antioxidant capacities (Shi et al., 2009; Jin et al., 2013; He et al., 2015; Koike et al., 2015; Tundis et al., 2015 ; Loizzo et al., 2016).

Herbaceous peony (Paeonia lactiflora Pall.) is a kind of plant with ornamental, edible and medicinal functions, and has lots of cultivars with different flower colors and types (Jia et al., 2008). The roots, leaves and flowers of herbaceous peony can be used to extract different components (Jia et al., 2008; Zhou et al., 2011; Ning et al., 2015; Jin et al., 2013; Feng et al., 2016). The medical function of herbaceous peony was recorded in ancient Chinese literatures which believed that herbaceous peony flower tea can nourish liver, regulate female endocrine and improve body immunity. For a long time, researches of herbaceous peony were mainly focused on flower ornamental characteristics (Jia et al., 2008) and root medicinal value (Hou et al., 2012),

\footnotetext{
${ }^{*}$ Corresponding author:

Chunhua Zhou, College of Horticulture and Plant Protection, Yangzhou University, Yangzhou 225009, China. E-mail: chzhou@yzu.edu.cn
}

Received: 09 May 2017; Revised: 21 June 2017; Accepted: 30 July 2017; Published Online: 12 August 2017 
especially the underlying mechanisms of flower coloration (Zhao et al., 2014; Wu et al., 2016; Zhao et al., 2016). However, few studies were concerned to edible value of herbaceous peony petals. Yu (2011) and Liu (2014) found that herbaceous peony petals containing lots of chemical compositions such as vitamins, protein, sugar, organic acid, as well as rich mineral elements and amino acids. In addition, herbaceous peony petals also contained a large number of total phenolics, flavonoids and other bioactive substances, which have a strong ability to eliminate free radicals (Jin et al., 2013). In this study, petal nutritional qualities of different cultivars at full bloom stage were investigated to screen out peony varieties with better edible quality. The research results may lay the foundation for the comprehensive utilization of herbaceous peony petals and edible herbaceous peony cultivation and development.

\section{PLANT MATERIALS AND METHODS}

\section{Plant materials}

Flowers of 46 P. lactiflora cultivars at full bloom stage were sampled from April to May, 2015 (Fig. 1). All the flower materials were collected from Peony Germplasm Resource Garden, College of Horticulture and Plant Protection, Yangzhou University, Jiangsu Province, China (32 $30^{\prime} \mathrm{N}$, $\left.119^{\circ} 25^{\prime} \mathrm{E}\right)$. The petals were detached from flowers, some petals were dried to a constant weight in an oven at $60^{\circ} \mathrm{C}$, and the rest petals were immediately frozen with liquid nitrogen and stored in a ultra-low temperature refrigerator under $-80^{\circ} \mathrm{C}$ until use.

\section{Methods}

\section{Determination of nutritional and bioactive component}

Soluble sugar content was determined by anthrone colorimetry at $630 \mathrm{~nm}$ wavelength (Liu \& Li, 2007). Organic acid content was determined by acid-base titration with $0.02 \mathrm{~mol} / \mathrm{L} \mathrm{NaOH}$ (Liu \& Li, 2007). Protein content was determined by Coomassie brilliant blue G-250 staining under $595 \mathrm{~nm}$ wavelength (Liu \& Li, 2007). Vitamin C (Vc) content was determined using 2,6-dichloro-indigo colorimetry until the solution color changed from blue to pink (Ahmed et al., 2014). Mineral element content was determined with a Thermo Fisher ICAP 6300 ICP instrument (Thermo Fisher, USA) according the method of Du et al. (2012) after nitric acid $\left(\mathrm{HNO}_{3}\right)$ digestion of dried petal samples. Amino acid content was determined with Biochrom 30 automatic amino acid analyzer (Biochrom, UK) after hydrochloric acid hydrolysis of dried petal samples according the method of Qureshi et al. (2014). The analyzed amino acid include threonine, valine, methionine, isoleucine, leucine, phenylalanine, lysine, aspartic acid, serine, glutamic acid, glycine, alanine, cysteine, tyrosine, arginine and proline. Total flavonoids were determined by $\mathrm{Al}\left(\mathrm{NO}_{3}\right)_{3}-\mathrm{NaNO}_{2}$ colorimetry method (He et al., 2015). Total phenolics were determined using Folin-Ciocalteu procedure (Huang et al., 2005). Superoxide dismutase (SOD) activity was measured with reagent kits from Nanjing Jiancheng Biological Co. Ltd. (Nanjing, China) according to the operation instruction. The amount corresponding to $50 \%$ SOD inhibition rate in $1 \mathrm{~mL}$ reaction mixture per gram fresh weight of petals. All above analysis were performed in triplicate.

\section{Statistical analysis}

Evaluation index screening was carried out based on cultivar variation and quality correlation analysis of $46 \mathrm{P}$. lactiflora cultivars using IBM SPSS 20 software (IBM, USA). The corresponding values of the principal components were obtained according to the expression calculation of the principal components. Case (Q type) analysis of principal components and cluster analysis of each cultivar were performed on the selected evaluation indexes with Ward's minimum-variance method and Euclidean distance, and then cultivars with better eating qualities were obtained.

\section{RESULTS}

\section{Evaluation index screening of nutritional components} The contents of four nutritional quality indexes in flower petals of 46 herbaceous peony cultivars and their average value, standard deviation and variation coefficient were listed in Table 1. The data showed that the average content of soluble sugar, organic acid, protein and Vc on fresh weight (FW) basis were $118.40 \pm 28.26 \mathrm{mg} / \mathrm{g}$ FW, $4.34 \pm 1.04 \mathrm{mg} / \mathrm{g} \mathrm{FW}, 51.39 \pm 30.28 \mathrm{mg} / \mathrm{g} \mathrm{FW}$, and $14.88 \pm 4.94 \mathrm{mg} / 100 \mathrm{~g} \mathrm{FW}$, respectively. The contents of four nutritional components varied with different cultivars, and their variation coefficient also differed from each other. Variation coefficient is the difference between cultivars, the higher the value, the greater the difference among cultivars. The variation coefficient of soluble sugar $(23.87 \%)$ and organic acid $(23.96 \%)$ was smaller. The variation coefficient of $\mathrm{Vc}$ was centered, with the value of $33.17 \%$. The variation coefficient of protein was the largest, reaching $58.92 \%$. The results showed that the difference of soluble sugar and organic acid content was smaller between cultivars, while the difference of protein and Vc content was much bigger. Protein and Vc content had great influence on the edible quality of different cultivars. Therefore, protein and Vc were screened as evaluation indexes of nutritional components.

\section{Evaluation index screening of bioactive components}

The content of three bioactive component quality indexes in flower petals of 46 herbaceous peony cultivars and their average value, standard deviation and variation 


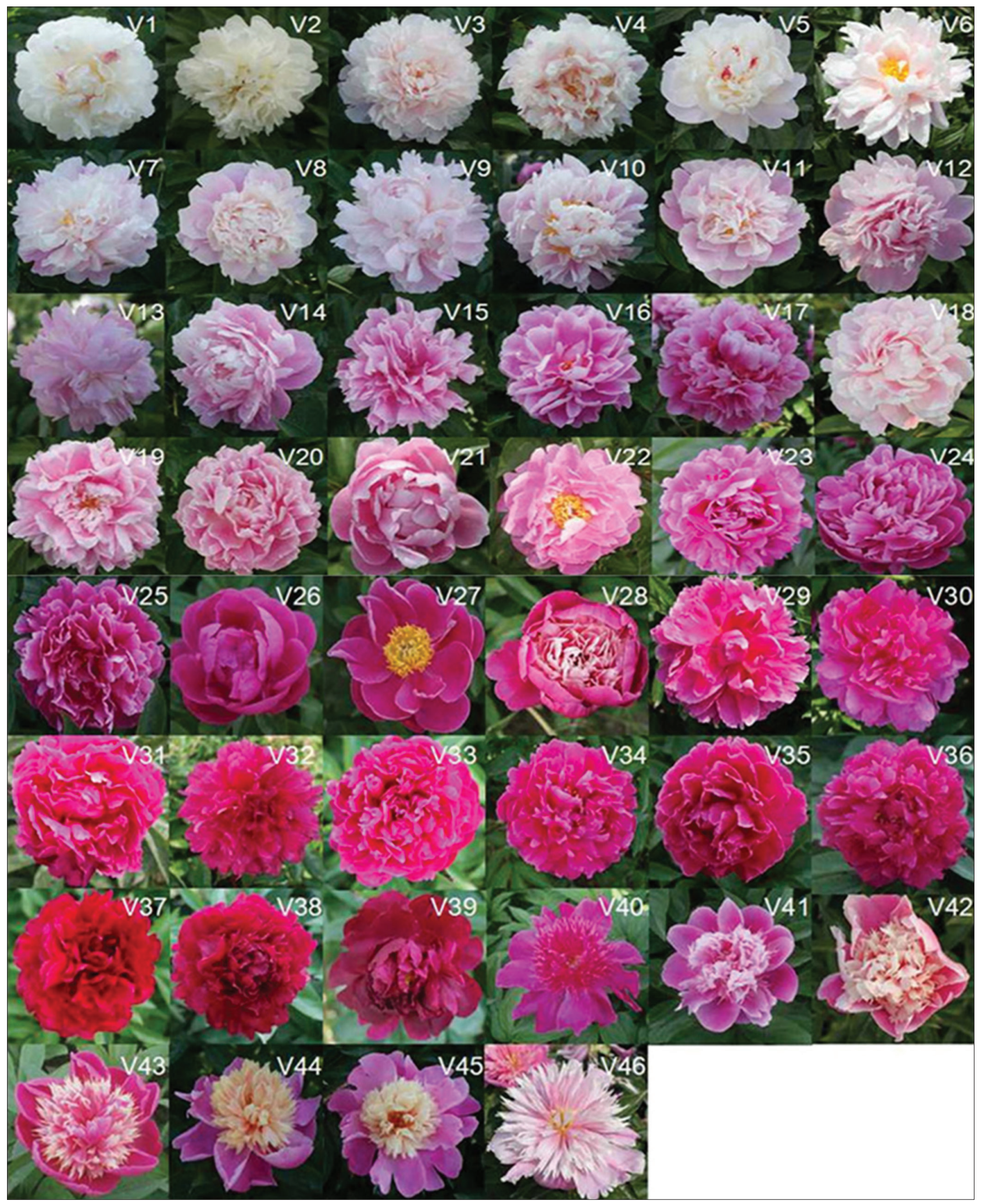

Fig 1. Flowers of 46 cultivars of $P$. lactiflora at full bloom stage.

Cultivars were ranged in order according to the color of flower petal from light to deep, with complex colors in the end. V1, 'Yulou Hongxing'; V2, 'Bingshan'; V3, 'Taohua Feixue'; V4, 'Zhushapan'; V5, 'Xishifen'; V6, 'Qili'; V7, 'Shengtaohua'; V8, 'Zhusha Dianyu'; V9, 'Fenpan Chengyan'; V10, 'Jingling Piaoxiang'; V11, 'Taohua Xijin'; V12, 'Fenlou Dianchun'; V13, 'Lanyu Huancui'; V14, 'Chenxi'; V15, 'Fenyinzhuang'; V16, 'Zilankui'; V17, 'Lanyu Jiaohui'; V18, 'Zhongshengfen'; V19, 'Taoli Yangzhuang'; 20, 'Ziyulian'; V21, 'Fenlanlou'; V22, 'Xixia Yinxue'; V23, 'Zhaoyuanhong'; V24, 'Hongyan Yushuang'; V25, 'Dadi Lushuang'; V26, 'Wulong Jisheng'; V27, 'Hongmanao'; V28, 'Dielian Qihua'; V29, 'Ziling Jinxing'; V30, 'Dafugui'; V31, 'Honglou'; V32, 'Niaochao'; V33, 'Hongyan Zhenghui'; V34, 'Zituo Ronghua'; V35, 'Huangguanfen'; V36, 'Honglou Piaoxiang'; V37, 'Yanzi Xiangyang'; V38, 'Xueyuan Honghua'; V39, 'Liehuo Jingang'; V40, 'Zifengyu'; V41, 'Zihong Jianrong'; V42, 'Huangxiuzhen'; V43, 'Jinlian Xianyu'; V44, 'Tailian'; V45, 'Zilou Xianjin'; V46, 'Zitan Xiangyu'. 
Table 1: Variation of nutritional components in different $P$. lactiflora cultivars

\begin{tabular}{|c|c|c|c|c|c|c|c|c|c|}
\hline No. & $\begin{array}{c}\text { Soluble sugar } \\
\text { (mg/g FW) }\end{array}$ & $\begin{array}{c}\text { Organic acid } \\
(\mathrm{mg} / \mathrm{g} \mathrm{FW})\end{array}$ & $\begin{array}{c}\text { Protein } \\
\text { (mg/g FW) }\end{array}$ & $\begin{array}{c}\mathrm{Vc} \\
(\mathrm{mg} / 100 \mathrm{~g} \mathrm{FW}) \\
\end{array}$ & No. & $\begin{array}{c}\text { Soluble sugar } \\
\text { (mg/g FW) }\end{array}$ & $\begin{array}{c}\text { Organic acid } \\
\text { (mg/g FW) }\end{array}$ & $\begin{array}{c}\text { Protein } \\
\text { (mg/g FW) }\end{array}$ & $\begin{array}{c}\text { Vc } \\
\text { (mg/100g FW) }\end{array}$ \\
\hline V1 & $177.28 \pm 2.61$ & $4.05 \pm 0.05$ & $11.06 \pm 2.34$ & $9.90 \pm 0.66$ & V25 & $111.62 \pm 3.73$ & $4.67 \pm 0.18$ & $95.97 \pm 2.25$ & $10.86 \pm 0.43$ \\
\hline V2 & $85.89 \pm 0.22$ & $4.50 \pm 0.05$ & $71.90 \pm 3.17$ & $11.52 \pm 0.75$ & V26 & $103.40 \pm 3.09$ & $3.90 \pm 0.18$ & $87.47 \pm 2.45$ & $16.42 \pm 1.18$ \\
\hline V3 & $103.53 \pm 3.77$ & $4.43 \pm 0.08$ & $53.30 \pm 4.44$ & $10.08 \pm 0.16$ & V27 & $120.05 \pm 3.23$ & $6.59 \pm 0.15$ & $57.67 \pm 2.81$ & $15.01 \pm 1.01$ \\
\hline V4 & $166.88 \pm 10.27$ & $4.50 \pm 0.05$ & $60.34 \pm 1.75$ & $11.13 \pm 0.85$ & V28 & $119.49 \pm 3.53$ & $5.41 \pm 0.11$ & $77.50 \pm 3.07$ & $15.17 \pm 0.79$ \\
\hline V5 & $75.13 \pm 5.23$ & $2.50 \pm 0.23$ & $48.02 \pm 2.61$ & $13.02 \pm 0.66$ & V29 & $142.82 \pm 1.39$ & $4.59 \pm 0.14$ & $33.82 \pm 10.39$ & $19.33 \pm 1.46$ \\
\hline V6 & $104.16 \pm 3.47$ & $4.35 \pm 0.05$ & $85.01 \pm 2.72$ & $12.81 \pm 1.19$ & V30 & $102.80 \pm 4.43$ & $6.60 \pm 0.13$ & $56.86 \pm 1.22$ & $15.95 \pm 1.46$ \\
\hline V7 & $130.82 \pm 11.52$ & $2.25 \pm 0.05$ & $36.43 \pm 1.07$ & $10.72 \pm 0.30$ & V31 & $107.66 \pm 1.54$ & $6.30 \pm 0.03$ & $72.50 \pm 6.84$ & $12.97 \pm 0.12$ \\
\hline V8 & $166.04 \pm 5.26$ & $4.77 \pm 0.18$ & $36.94 \pm 0.25$ & $10.34 \pm 0.49$ & V32 & $82.11 \pm 2.65$ & $4.33 \pm 0.18$ & $121.56 \pm 1.73$ & $20.09 \pm 0.28$ \\
\hline V9 & $141.62 \pm 9.94$ & $4.87 \pm 0.14$ & $48.33 \pm 0.75$ & $14.67 \pm 0.96$ & V33 & $110.99 \pm 3.46$ & $4.51 \pm 0.03$ & $58.44 \pm 1.43$ & $19.12 \pm 0.70$ \\
\hline V10 & $93.41 \pm 0.84$ & $2.71 \pm 0.03$ & $46.85 \pm 5.21$ & $12.26 \pm 0.09$ & V34 & $108.99 \pm 0.60$ & & $49.38 \pm 4.06$ & $20.24+$ \\
\hline V11 & $98.49 \pm 3.15$ & $4.35 \pm 0.15$ & $26.27 \pm 1.29$ & $12.29 \pm 0.67$ & V35 & $93.81 \pm 3.40$ & $3.07 \pm 0.04$ & $54.16 \pm 2.37$ & $17.74 \pm 1.46$ \\
\hline V12 & $111.13 \pm 1.58$ & $6.00 \pm 0.35$ & $103.07 \pm 2.83$ & $14.51 \pm 0.98$ & V36 & $116.00 \pm 4.59$ & $6.90 \pm 0.24$ & $74.26 \pm 2.49$ & $30.23 \pm 0.99$ \\
\hline V13 & $93.04 \pm 2.45$ & $2.70 \pm 0.10$ & $28.87 \pm 1.72$ & $11.23 \pm 0.18$ & V37 & $109.12 \pm 1.66$ & $4.95 \pm 0.10$ & $50.15 \pm 3.89$ & $24.02 \pm 1.03$ \\
\hline V14 & $127.48 \pm 1.71$ & $2.72 \pm 0.03$ & $7.39 \pm 0.36$ & $12.00 \pm 0.16$ & V38 & $109.99 \pm 3.64$ & $5.67 \pm 0.18$ & $98.39 \pm 2.19$ & $25.59 \pm 1.95$ \\
\hline V15 & $132.45 \pm 1.05$ & $2.98 \pm 0.21$ & $23.83 \pm 0.95$ & $10.52 \pm 0.38$ & V39 & $148.99 \pm 2.60$ & $5.89 \pm 0.14$ & $107.62 \pm 2.23$ & $30.24 \pm 0.87$ \\
\hline V16 & $175.16 \pm 3.72$ & $4.80 \pm 0.18$ & $16.11 \pm 1.55$ & $12.88 \pm 0.88$ & V40 & $166.85 \pm 1.92$ & $5.58 \pm 0.24$ & $6.53 \pm 0.59$ & $20.45 \pm 0.37$ \\
\hline V17 & $66.55 \pm 4.62$ & $2.60 \pm 0.10$ & $40.26 \pm 1.50$ & $14.80 \pm 0.71$ & V41 & $156.81 \pm 2.41$ & $4.88 \pm 0.11$ & $21.03 \pm 1.87$ & $12.87 \pm 0.12$ \\
\hline V18 & $97.94 \pm 2.17$ & $4.38 \pm 0.13$ & $12.21 \pm 0.43$ & $10.56 \pm 1.13$ & V42 & $115.79 \pm 4.46$ & $2.19 \pm 0.05$ & $45.73 \pm 0.60$ & $14.74 \pm 0.32$ \\
\hline V19 & $72.15 \pm 1.58$ & $4.35 \pm 0.15$ & $32.60 \pm 2.01$ & $14.39 \pm 0.55$ & V43 & $113.19 \pm 3.09$ & $4.14 \pm 0.08$ & $82.20 \pm 1.22$ & $12.05 \pm 0.47$ \\
\hline V20 & $115.24 \pm 2.92$ & $4.68 \pm 0.24$ & $34.70 \pm 2.66$ & $12.52 \pm 0.13$ & V44 & $106.26 \pm 3.62$ & $2.73 \pm 0.07$ & $40.57 \pm 3.54$ & $11.86 \pm 0.09$ \\
\hline V21 & $100.06 \pm 0.77$ & $3.48 \pm 0.13$ & $21.30 \pm 1.02$ & $9.77 \pm 0.38$ & V45 & $90.67 \pm 1.90$ & $2.68 \pm 0.06$ & $10.97 \pm 1.99$ & $12.04 \pm 1.10$ \\
\hline V22 & $130.19 \pm 2.63$ & $3.30 \pm 0.15$ & $79.36 \pm 3.12$ & $13.31 \pm 0.17$ & V46 & $168.04 \pm 3.00$ & $4.53 \pm 0.10$ & $8.20 \pm 1.36$ & $12.33 \pm 0.62$ \\
\hline V23 & $153.63 \pm 5.29$ & $5.88 \pm 0.40$ & $28.40 \pm 2.41$ & $14.98 \pm 1.10$ & Average & $118.40 \pm 28.26$ & $4.34 \pm 1.04$ & $51.39 \pm 30.28$ & $14.88 \pm 4.94$ \\
\hline V24 & $122.54 \pm 1.56$ & $3.60 \pm 0.20$ & $100.29 \pm 2.63$ & $15.07 \pm 0.61$ & $\mathrm{CV}(\%)$ & 23.87 & 23.96 & 58.92 & 33.20 \\
\hline
\end{tabular}

All analysis were carried out triplicate and based on fresh weight (FW), the average content was the mean value of 46 cultivars, CV means cultivar variation

Table 2: Variation of active ingredients in different $\boldsymbol{P}$. lactiflora cultivars

\begin{tabular}{|c|c|c|c|c|c|c|c|}
\hline No. & $\begin{array}{c}\text { Total phenolics } \\
\text { (mg/g DW) }\end{array}$ & $\begin{array}{c}\text { Total flavonoids } \\
\text { (mg/g DW) }\end{array}$ & SOD (U/g FW) & No. & $\begin{array}{c}\text { Total phenolics } \\
\text { (mg/g DW) }\end{array}$ & $\begin{array}{c}\text { Total flavonoids } \\
\text { (mg/g DW) }\end{array}$ & SOD (U/g FW) \\
\hline V1 & $16.62 \pm 0.54$ & $14.40 \pm 0.42$ & $456.84 \pm 7.47$ & V25 & $21.41 \pm 1.26$ & $7.93 \pm 1.45$ & $398.63 \pm 15.20$ \\
\hline V2 & $21.28 \pm 0.10$ & $7.44 \pm 0.09$ & $500.00 \pm 4.34$ & V26 & $23.46 \pm 0.90$ & $7.08 \pm 0.25$ & $456.84 \pm 7.47$ \\
\hline V3 & $20.18 \pm 1.31$ & $6.47 \pm 0.41$ & $379.34 \pm 11.61$ & V27 & $23.39 \pm 1.00$ & $11.53 \pm 1.33$ & $377.29 \pm 1.81$ \\
\hline V4 & $25.41 \pm 0.90$ & $8.52 \pm 0.08$ & $455.54 \pm 8.13$ & V28 & $14.55 \pm 1.82$ & $6.21 \pm 0.29$ & $418.33 \pm 4.63$ \\
\hline V5 & $12.79 \pm 0.38$ & $8.75 \pm 0.40$ & $462.60 \pm 7.88$ & V29 & $15.06 \pm 0.63$ & $5.50 \pm 0.06$ & $402.13 \pm 3.79$ \\
\hline V6 & $15.72 \pm 1.02$ & $12.69 \pm 0.25$ & $472.85 \pm 3.53$ & V30 & $16.69 \pm 0.69$ & $6.38 \pm 0.51$ & $426.27 \pm 12.17$ \\
\hline V7 & $23.06 \pm 0.71$ & $11.37 \pm 0.04$ & $386.76 \pm 18.95$ & V31 & $21.10 \pm 0.20$ & $7.42 \pm 0.07$ & $442.95 \pm 7.65$ \\
\hline V8 & $22.02 \pm 1.47$ & $16.45 \pm 0.37$ & $447.50 \pm 6.32$ & V32 & $11.30 \pm 0.69$ & $9.19 \pm 1.30$ & $429.16 \pm 9.63$ \\
\hline V9 & $17.99 \pm 0.34$ & $3.50 \pm 0.29$ & $345.05 \pm 12.23$ & V33 & $33.01 \pm 0.50$ & $8.59 \pm 0.72$ & $464.85 \pm 9.36$ \\
\hline V10 & $15.43 \pm 1.35$ & $11.81 \pm 0.46$ & $496.45 \pm 9.07$ & V34 & $16.08 \pm 1.87$ & $6.92 \pm 0.38$ & $480.16 \pm 10.21$ \\
\hline V11 & $21.12 \pm 0.15$ & $11.82 \pm 1.09$ & $456.90 \pm 9.47$ & V35 & $31.10 \pm 0.19$ & $7.92 \pm 0.94$ & $498.30 \pm 3.79$ \\
\hline V12 & $32.23 \pm 0.61$ & $10.30 \pm 0.75$ & $442.49 \pm 5.88$ & V36 & $23.16 \pm 0.83$ & $6.82 \pm 0.35$ & $381.57 \pm 9.72$ \\
\hline V13 & $14.22 \pm 0.64$ & $6.35 \pm 0.53$ & $466.57 \pm 9.50$ & V37 & $21.37 \pm 1.51$ & $7.68 \pm 0.19$ & $439.31 \pm 7.88$ \\
\hline V14 & $9.41 \pm 0.84$ & $8.51 \pm 0.64$ & $434.76 \pm 6.11$ & V38 & $28.53 \pm 0.60$ & $6.64 \pm 0.55$ & $465.00 \pm 12.50$ \\
\hline V15 & $24.70 \pm 0.06$ & $7.88 \pm 0.41$ & $413.00 \pm 6.78$ & V39 & $22.41 \pm 2.10$ & $5.49 \pm 0.29$ & $305.62 \pm 16.20$ \\
\hline V16 & $20.48 \pm 1.31$ & $7.12 \pm 0.07$ & $469.40 \pm 10.00$ & V40 & $14.74 \pm 1.77$ & $5.52 \pm 0.42$ & $443.73 \pm 13.99$ \\
\hline V17 & $21.51 \pm 0.37$ & $8.22 \pm 0.23$ & $490.90 \pm 6.16$ & V41 & $30.51 \pm 2.05$ & $7.34 \pm 0.20$ & $475.40 \pm 10.28$ \\
\hline V18 & $27.69 \pm 1.73$ & $8.29 \pm 0.45$ & $462.60 \pm 7.88$ & V42 & $31.98 \pm 0.92$ & $9.48 \pm 0.53$ & $463.36 \pm 8.68$ \\
\hline V19 & $20.23 \pm 0.84$ & $8.28 \pm 0.36$ & $449.08 \pm 6.18$ & V43 & $18.35 \pm 1.15$ & $8.97 \pm 0.17$ & $520.42 \pm 7.05$ \\
\hline V20 & $21.72 \pm 0.70$ & $8.17 \pm 0.40$ & $447.15 \pm 2.67$ & V44 & $30.92 \pm 0.76$ & $8.66 \pm 0.19$ & $474.53 \pm 7.50$ \\
\hline V21 & $11.97 \pm 1.53$ & $8.63 \pm 0.30$ & $356.97 \pm 9.20$ & V45 & $12.72 \pm 0.77$ & $7.71 \pm 0.64$ & $415.48 \pm 9.51$ \\
\hline V22 & $11.16 \pm 0.87$ & $17.56 \pm 1.02$ & $448.63 \pm 5.48$ & V46 & $13.84 \pm 0.83$ & $8.52 \pm 0.52$ & $399.51 \pm 9.20$ \\
\hline V23 & $12.51 \pm 1.91$ & $8.53 \pm 0.09$ & $448.63 \pm 5.48$ & Average & $19.17 \pm 6.36$ & $8.27 \pm 2.83$ & $433.18 \pm 44.79$ \\
\hline V24 & $15.83 \pm 0.20$ & $13.66 \pm 0.08$ & $504.35 \pm 5.50$ & CV(\%) & 33.18 & 34.22 & 10.34 \\
\hline
\end{tabular}

All analysis were carried out triplicate, total phenolics and total flavonoids analysis were based on dry weight (DW), while SOD (Superoxide dismutase) analysis were basesd on fresh weight (FW), the average content was the mean value of 46 cultivars, CV means cultivar variation 
coefficient were listed in Table 2. The data showed that the average content of total phenolics and flavonoids were $19.17 \pm 6.36 \mathrm{mg} / \mathrm{g}$ DW and $8.27 \pm 2.83 \mathrm{mg} / \mathrm{g}$ DW, respectively. The average value of SOD activity was 433.18 $\pm 44.79 \mathrm{U} / \mathrm{g}$ DW. Among different cultivars, the variation coefficient of SOD activity $(10.34 \%)$ was smaller, while those of total phenolics and flavonoids were much bigger, with the value of $33.18 \%$ and $34.22 \%$, respectively. The results showed that the difference of SOD activity was smaller between cultivars, while the difference of total phenolics and flavonoids were much bigger. Therefore, total phenolics and flavonoids were screened as evaluation indexes of bioactive components.

The correlation coefficient analysis was performed between 7 quality indexes in Table 1 and Table 2. The larger the correlation coefficient between two indexes, the more related between them. Therefore, one of them can be selected as a representative index of evaluation, as the basis for the simplified index (Yang et al., 2011). From the results, we found that the correlation coefficients between 7 quality indexes were all less than 0.5 whether it is positive or negative correlation (Table 3). The correlation between Vc, protein, total phenolics and flavonoids were lower and can't be simplified. Combined with the data of Table 1, Table 2 and Table 3, protein, $\mathrm{Vc}$, total phenolics and total flavonoids were screened as the evaluation indexes of the nutritional components and the bioactive ingredients.

\section{Evaluation index screening of mineral elements}

The contents of 10 mineral elements in the flower petals of different herbaceous peony cultivars were shown in Table 4. $\mathrm{Na}, \mathrm{Mg}, \mathrm{K}, \mathrm{Ca}, \mathrm{Mn}, \mathrm{Fe}, \mathrm{Ni}$ and $\mathrm{Zn}$ were found in the flower petals of 46 cultivars, and Mo, Cr were detected in the flower petals of most cultivars. The variation coefficients of $\mathrm{Na}, \mathrm{Mg}, \mathrm{K}$ and $\mathrm{Ca}(22.67 \%, 28.70 \%, 22.02 \%$ and $35.77 \%)$ were lower than those of other mineral elements. The variation coefficients of $\mathrm{Mn}$ and $\mathrm{Zn}$ arranged in the middle, with the value of $78.92 \%$ and $73.16 \%$. The variation coefficients of $\mathrm{Fe}, \mathrm{Ni}, \mathrm{Mo}$ and $\mathrm{Cr}$ were larger and all more than $100 \%$. The results indicated that six mineral elements including $\mathrm{Fe}, \mathrm{Ni}, \mathrm{Mo}, \mathrm{Cr}, \mathrm{Mn}$ and $\mathrm{Zn}$ had a greater effect on cultivar differences.
The correlation between ten analyzed mineral elements was carried out (Table 5). There was significant correlation $p<0.01$ between $\mathrm{Mn}$ and $\mathrm{Fe}, \mathrm{Ni}, \mathrm{Cr}, \mathrm{Mo}$, and the correlation coefficients were all more than 0.9. There was also significant correlation $p<0.01$ between $\mathrm{Mg}$ and $\mathrm{K}, \mathrm{Ca}, \mathrm{Zn}$, and the correlation coefficients were all more than $0.7 . \mathrm{Na}$ had no obvious relation with other mineral elements. Mn, $\mathrm{Fe}, \mathrm{Ni}, \mathrm{Cr}$ and Mo had close correlation, $\mathrm{Mg}, \mathrm{K}, \mathrm{Ca}, \mathrm{Zn}$ also had close correlation, so one element can be selected from each group to represent them. Because Fe and $\mathrm{Zn}$ have a very important role in the human body, so Fe and $\mathrm{Zn}$ were screened to represent the 6 elements. Combined with the data of Table 4 and Table 5, Fe and $\mathrm{Zn}$ were selected as the evaluation indexes of mineral elements.

\section{Evaluation index screening of amino acids}

All 17 amino acids were found in the flower petals of 46 herbaceous peony cultivars, and individual amino acid content and proportion varied with different cultivars. The total amino acids was from $8.68 \mathrm{~g} / 100 \mathrm{~g}$ DW to $9.09 \mathrm{~g} / 100 \mathrm{~g}$ DW, with essential amino acids accounting for about $42 \%$. The variation coefficients of 17 amino acids varied with different cultivars (Table 6). The difference of $\mathrm{Thr}$ (threonine), Val (valine), Ile (isoleucine), Leu (leucine), Gly (glycine), His (histidine) and Arg (arginine) between cultivars were smaller, the difference of Asp (aspartic acid), Ser (serine), Glu (glutamic acid), Ala (alanine), Cys (cysteine) and Tyr (tyrosine), Pro (proline) between cultivars were in the middle, while the variation coefficients of Lys (lysine), Met (methionine) and Phe (Phenylalanine) between cultivars differed greatly.

The correlation analysis between 17 amino acids was performed (Table 7). There was significant correlation $p<0.01$ between threonine, valine, isoleucine, leucine, lysine, aspartic acid, serine, glutamic acid, glycine, alanine, proline, and the correlation coefficients were more than $70 \%$, with most more than $85 \%$. There was also significant correlation $p<0.01$ between tyrosine and histidine, and the correlation coefficients was $80 \%$. There was no obvious relation between methionine, phenylalanine, cysteine, and arginine acid, as well as between them and other amino acids. This showed that 17 amino acids can be represented by 6 amino acids. Combined with the data of Table 6 and

Table 3: Correlation matrix of the 7 quality parameters in different $\boldsymbol{P}$. lactiflora cultivars

\begin{tabular}{lcccccc}
\multicolumn{1}{c}{} & Soluble sugar & Organic acid & Protein & Vc & Total phenolics & Total flavonoids \\
\hline Soluble sugar & & & & & & \\
Organic acid & $0.278^{* *}$ & & & & \\
Protein & $-0.272^{\star *}$ & $0.296^{* *}$ & & & \\
Vc & -0.003 & $0.472^{* *}$ & $0.408^{* *}$ & & & \\
Total phenolics & -0.020 & 0.098 & 0.140 & 0.126 & & \\
Total flavonoids & 0.102 & $-0.247^{* *}$ & 0.058 & $-0.350^{* *}$ & -0.082 & $0.274^{* *}$ \\
SOD & $-0.227^{* *}$ & $-0.302^{* *}$ & -0.014 & $-0.234^{* *}$ & 0.147 & \\
\hline
\end{tabular}

${ }^{\star *}$ Means significant correlation at the 0.01 level (2-tailed) 
ร

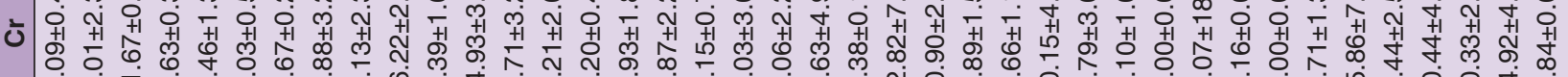
ம ம்

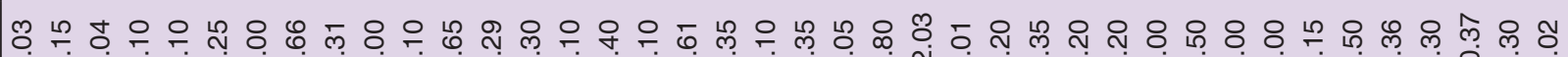

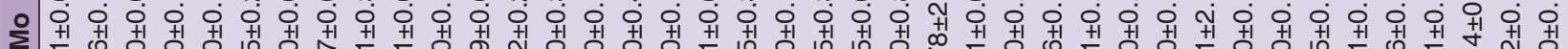

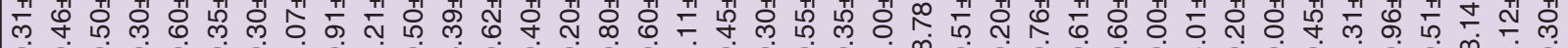

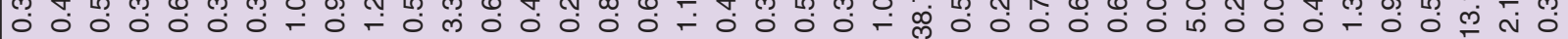

춘 ఐ N

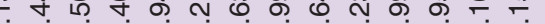

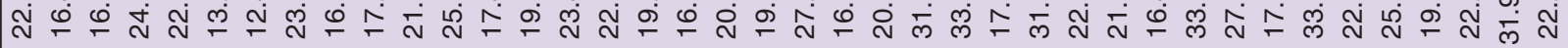

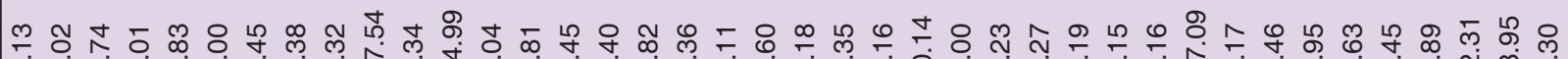

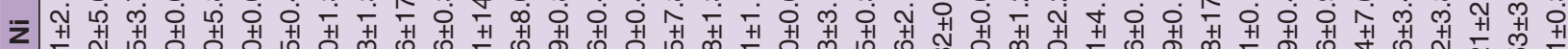

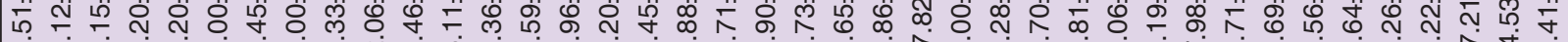
○ ம

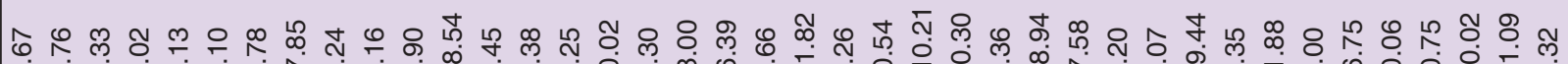
एँ

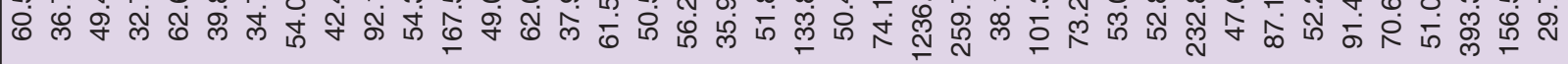

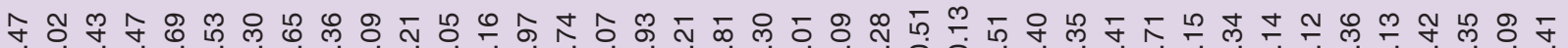

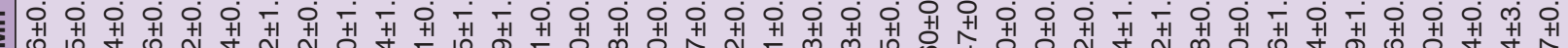

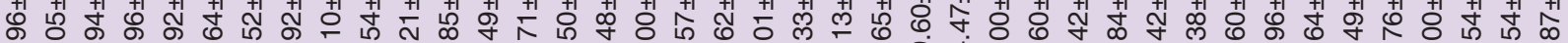

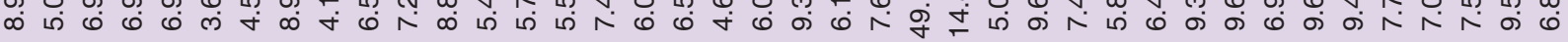

궁

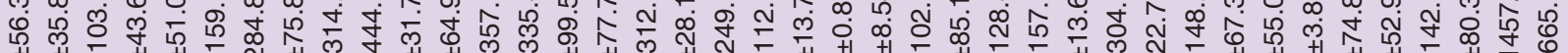
S

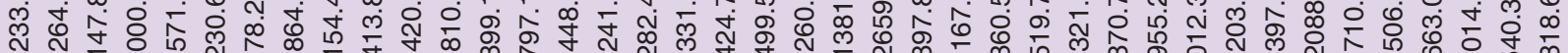

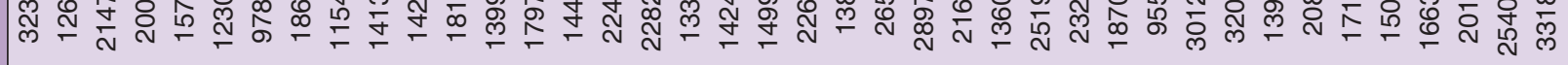

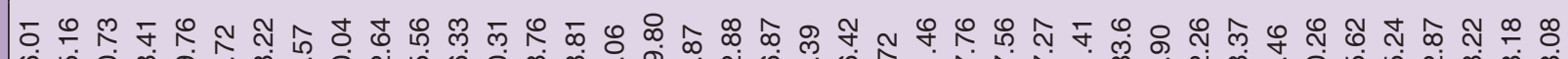

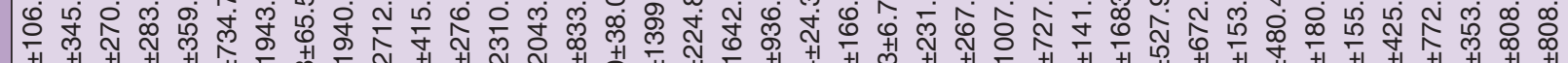

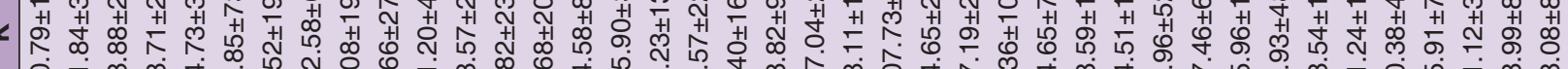
눈

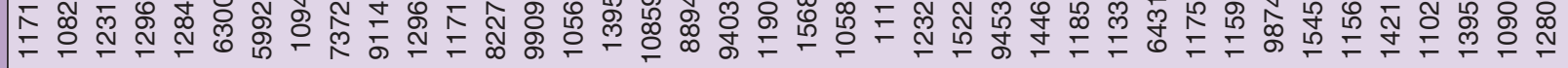

లి

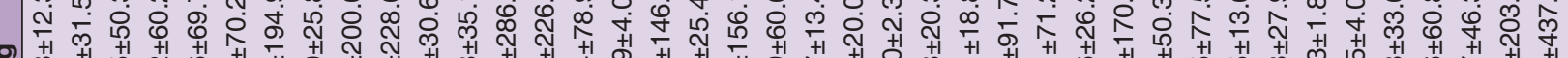

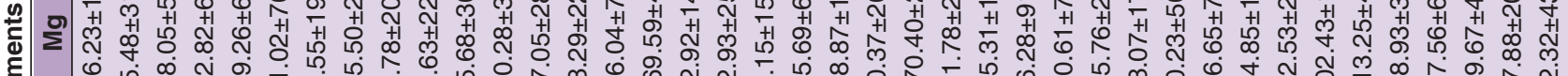

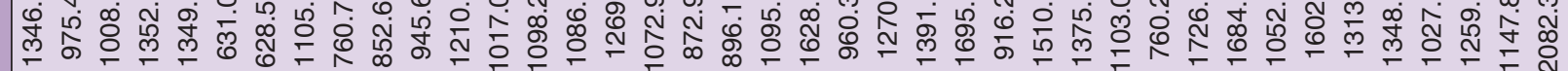

ఇ

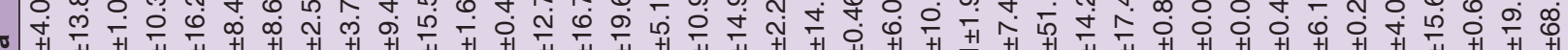
c 产 


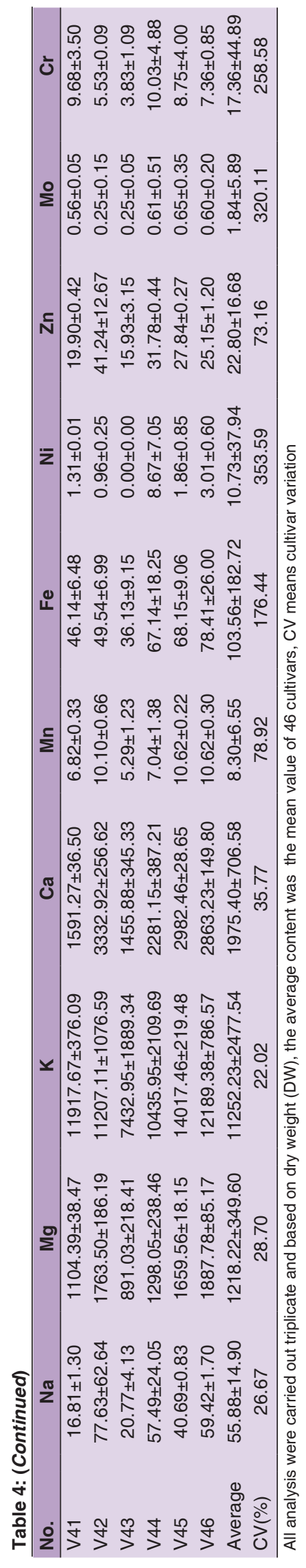

Table 7, Lys, Tyr, Met and Phe were choosed to on behalf of the 17 amino acids in the flower petals of herbaceous peony.

In summary, protein, $\mathrm{Vc}$, total phenolics, total flavonoids, $\mathrm{Fe}, \mathrm{Zn}$, Lys, Tyr, Met and Phe were screened as physiological indexes for evaluating flower petal edible quality of herbaceous peony. The SPSS software was used to perform the principal component analysis and cluster analysis of 10 kinds of nutrients in the flower petals of 46 herbaceous peony cultivars.

Analysis of principal component characteristic value, contribution rate and cumulative contribution rate

The SPSS software was used to perform the principal component analysis of 10 kinds of nutrients in the flower petals of 46 herbaceous peony cultivars, and the cumulative variance contribution rate of the main component reached $82.77 \%$, which explained the vast majority of the original information (Table 8). Eigenvalue of the first principal component was 2.547 , and variance contribution rate was $19.164 \%$, which represented $19.164 \%$ of all quality traits information. Eigenvalue of the second principal component was 1.501 , and variance contribution rate was $16.677 \%$, which represented $16.677 \%$ of all quality traits information. Eigenvalue of the third principal component was 1.364, and variance contribution rate was $13.664 \%$, which represented $13.664 \%$ of all quality traits information. Eigenvalue of the fourth principal component was 1.024, and variance contribution rate was $12.477 \%$, which represented $12.477 \%$ of all quality traits information. Other principal component contribution rate were $10.399 \%$ and $10.385 \%$, and they decreased gradually. The variance contribution rate of principal components showed that flower petal quality of herbaceous peony was influenced by many kinds of quality indexes, and the weight of each principal component was no much difference.

\section{Analysis of principal component factor load matrix}

The load matrix of the principal components and the original quality indexes clarified the weight of each quality index in the principal component. Therefore, the comprehensive quality index represented by principal component was judged according to the load of each quality index in each principal component. The load matrix of principal components on each quality index was showed in Table 9, and effects of the first 6 principal components reflected indexes were different in the determination of the nutritional quality of peony petals. The first principal components had greater load value on tyrosine and lysine contents, which showed that the first principal components mainly reflect the comprehensive index level of various amino acid contents in flower 
Table 5: Correlation matrix of the mineral elements

\begin{tabular}{|c|c|c|c|c|c|c|c|c|c|c|}
\hline & $\mathrm{Na}$ & $\mathrm{Mg}$ & $K$ & $\mathrm{Ca}$ & Mn & $\mathrm{Fe}$ & $\mathrm{Ni}$ & $\mathrm{Zn}$ & Mo & $\mathrm{Cr}$ \\
\hline \multicolumn{11}{|l|}{$\mathrm{Na}$} \\
\hline $\mathrm{Mg}$ & $0.413^{\star *}$ & & & & & & & & & \\
\hline K & $0.421^{\star *}$ & $0.747^{* *}$ & & & & & & & & \\
\hline $\mathrm{Ca}$ & $0.333^{\star *}$ & $0.833^{\star *}$ & $0.545^{\star *}$ & & & & & & & \\
\hline $\mathrm{Mn}$ & $0.371^{* *}$ & $0.318^{* *}$ & $0.288^{* *}$ & $0.401^{* *}$ & & & & & & \\
\hline $\mathrm{Fe}$ & $0.320^{* *}$ & $0.168^{*}$ & $0.192^{*}$ & $0.255^{* *}$ & $0.933^{\star *}$ & & & & & \\
\hline $\mathrm{Ni}$ & $0.262^{\star *}$ & 0.086 & 0.067 & $0.213^{*}$ & $0.930^{* *}$ & $0.951^{\text {** }}$ & & & & \\
\hline $\mathrm{Zn}$ & $0.560^{* *}$ & $0.724^{\star *}$ & $0.607^{* *}$ & $0.689^{* *}$ & $0.421^{\star *}$ & $0.298^{* *}$ & $0.216^{\star}$ & & & \\
\hline Mo & $0.228^{\star *}$ & 0.098 & 0.124 & $0.212^{*}$ & $0.898^{\star \star}$ & $0.979^{* *}$ & $0.958^{\star \star}$ & $0.211^{*}$ & & \\
\hline $\mathrm{Cr}$ & $0.248^{\star *}$ & 0.109 & 0.131 & $0.228^{\star *}$ & $0.910^{\star *}$ & $0.981^{* *}$ & $0.970^{\star * *}$ & $0.229^{\star *}$ & $0.997^{* *}$ & \\
\hline
\end{tabular}

${ }^{* \star}$ Means significant correlation at the 0.01 level (2-tailed), and * means significant correlation at the 0.05 level (2-tailed)

petals. The second principal components had greater load value on phenylalanine and protein contents. The third principal components had greater load value on total flavonoids and Vc contents, and the total flavonoids had larger positive correlation coefficient, and Vc had larger negative correlation coefficient. The fourth principal components had greater load value on Fe and Zn contents, which showed that the fourth principal components mainly reflect the comprehensive index level of various mineral elements in flower petals. The fifth principal components had greater load value on methionine content. The sixth principal component had greater load value on total phenolics content.

\section{Comparison of the quality scores of principal components}

The data of factor load matrix between the principal components and the quality indexes were input SPSS data editing window, and 6 principal component variables were named as al, a2, a3, a4, a5 and a6. Standard feature vector tij was constructed, which was represented by tij, and was calculated by the formula tij=aij $/ \sqrt{\lambda} \mathrm{i}$. At the same time, the original data of 10 quality indexes of 46 peony cultivars were standardized, eliminating the influence of different measurement unit and data dimension. The principal components were calculated with eigenvector matrix and standardized data with the formula $\mathrm{F}=\mathrm{t} \times \mathrm{ZX}$, where $\mathrm{F} 1 \sim \mathrm{F} 6$ was the 6 principal component, and ZX1 ZX10 was the standardized numerical value of the original data of 10 quality indexes in Table 10.

According to variance contribution rate of each principal components (the first principal component $19.164 \%$, the second principal component $16.677 \%$, the third principal component $13.664 \%$, the fourth principal component $12.477 \%$, the five principal component $10.399 \%$, the six principal component $10.385 \%$ ), the comprehensive score function $(\mathrm{F})$ was calculated with following formula:

$\mathrm{F}=0.19 \times \mathrm{F} 1+0.17 \times \mathrm{F} 2+0.14 \times \mathrm{F} 3+0.12 \times \mathrm{F} 4+0.10 \times \mathrm{F} 5+0$ $.10 \times \mathrm{F} 6$.
Plugged the corresponding principal components into above formula, we got the following comprehensive score formula.

$\mathrm{F}=0.15 \times \mathrm{Tyr}+0.12 \times$ Lys $+0.14 \times$ protein $+0.12 \times \mathrm{Phe}+$ $0.11 \times$ total flavonoids $-0.01 \times \mathrm{Vc}+0.15 \times \mathrm{Zn}+0.15 \times \mathrm{Fe}+$ $0.11 \times$ Met $+0.13 \times$ total phenolics.

The principal components comprehensive score of each cultivar and their rank was listed in Table 11. The higher the comprehensive score, the better the quality. On the contrary, the lower the score, the worse the quality. In order to facilitate subsequent comparison, the ranking table was divided into three sections. Cultivars in the top ten were in the first section. Cultivars in the last ten were in the third section. Rest cultivars were in the second section. The flower petal qualities of 46 herbaceous peony cultivars were evaluated according to the comprehensive score of the principal component analysis. Cultivars in the first section included 'Dielian Qihua', 'Zhushapan', 'Xueyuan Honghua', 'Wulong Jisheng', 'Honglou', 'Binshan', 'Hongyan Yushuang', 'Zituo Ronghua', 'Zifengyu' and 'Fenlou Dianchun'. Cultivars in the third section included 'Zhongshengfen', 'Honglou Piaoxiang', 'Dafugui', 'Taoli Yanzhuang', 'Zilankui', 'Jinling Piaoxiang', 'Chenxi', 'Shengtaohua', 'Fenpen Chengyan' and 'Yulan Huancui'. Rest cultivars ranked in the middle and were in the second section.

\section{Cluster analysis of different herbaceous peony cultivars}

Principal component cluster analysis of different cultivars was demenstrated in Fig. 2. 46 herbaceous peony cultivars can be divided into different types with different class separation distance. When the class separation distance was ten, 46 herbaceous peony cultivars can be divided into three categories. The category closer to the top of the figure aggregated 10 cultivars, including V14, V19, V16, V9, V30, V11 V22, V7, V10 and V13, containing lower contents of total flavonoids, total phenolics, mineral elements such as iron, zinc and amino acid, with poorer 
ᄂ 車

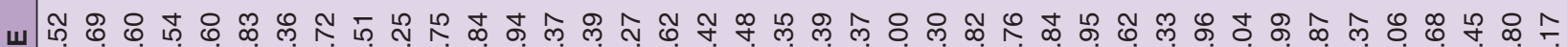
ल म

응 స్

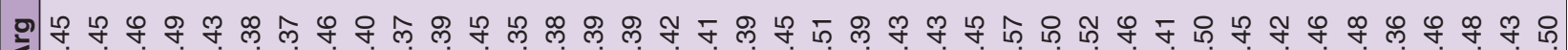

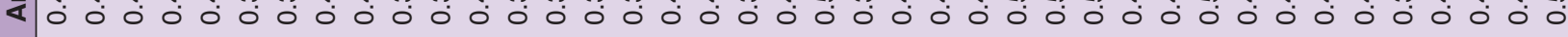

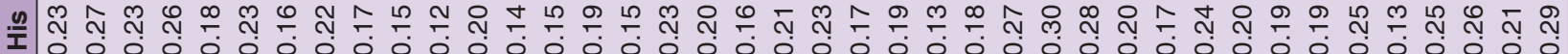

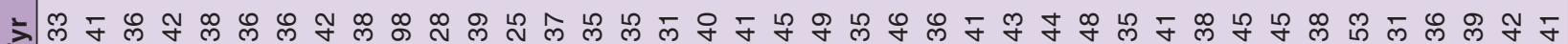

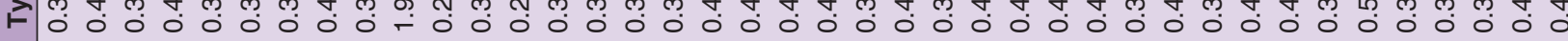

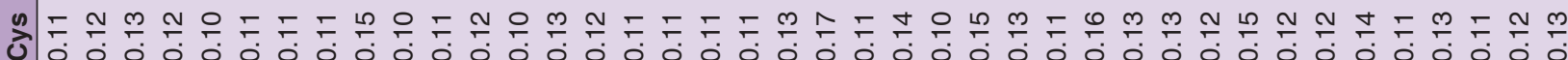

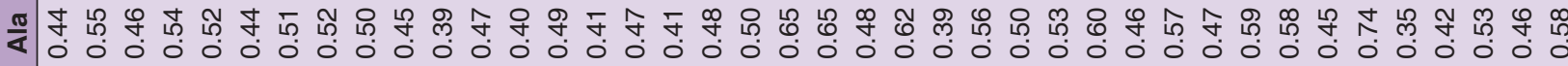

굽

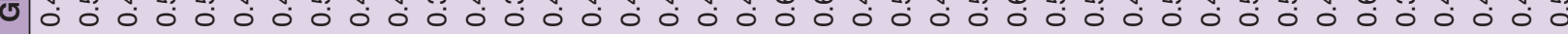

근

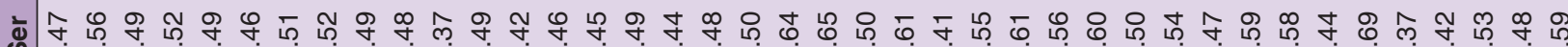

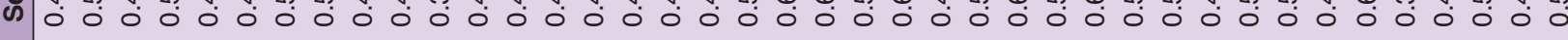
๗

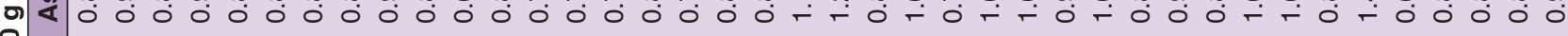

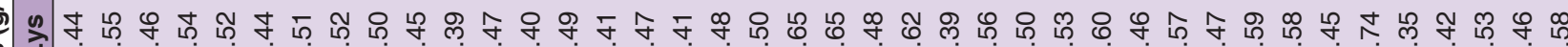

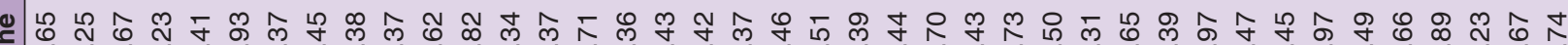

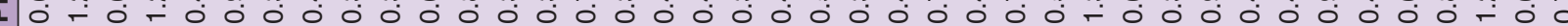

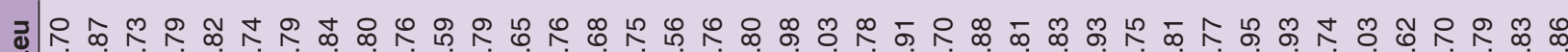
:

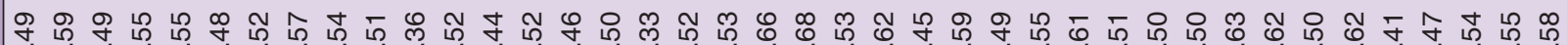

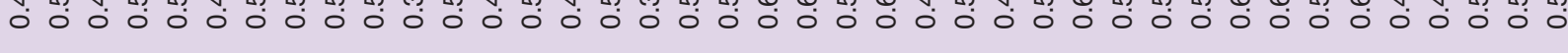

는 음

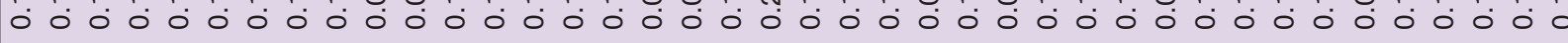

๘ ธ。

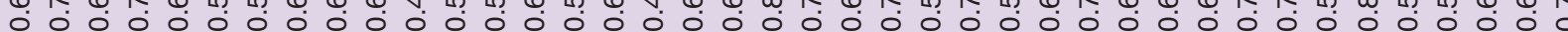

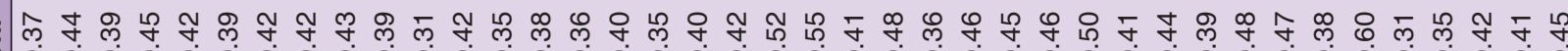

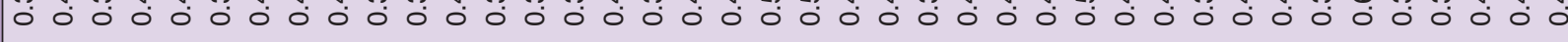




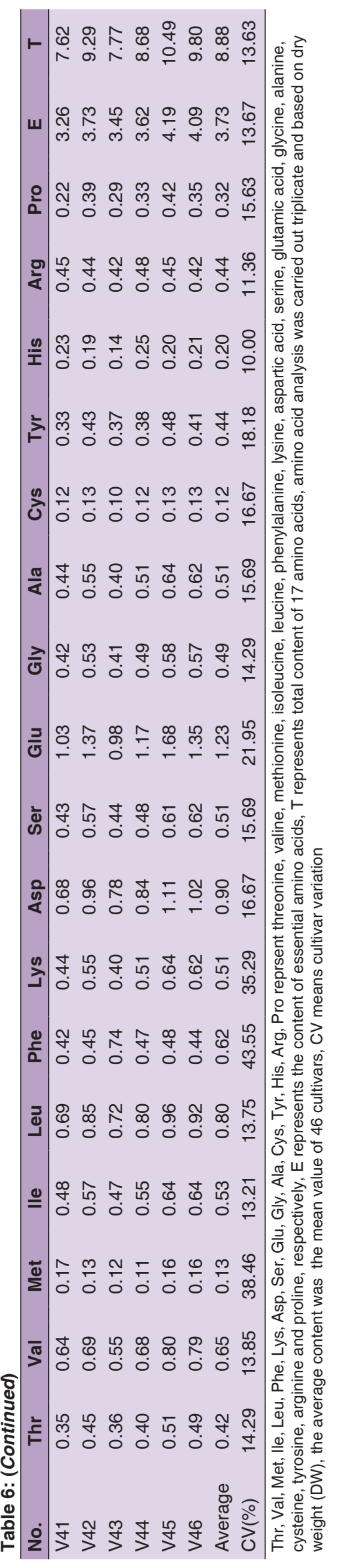

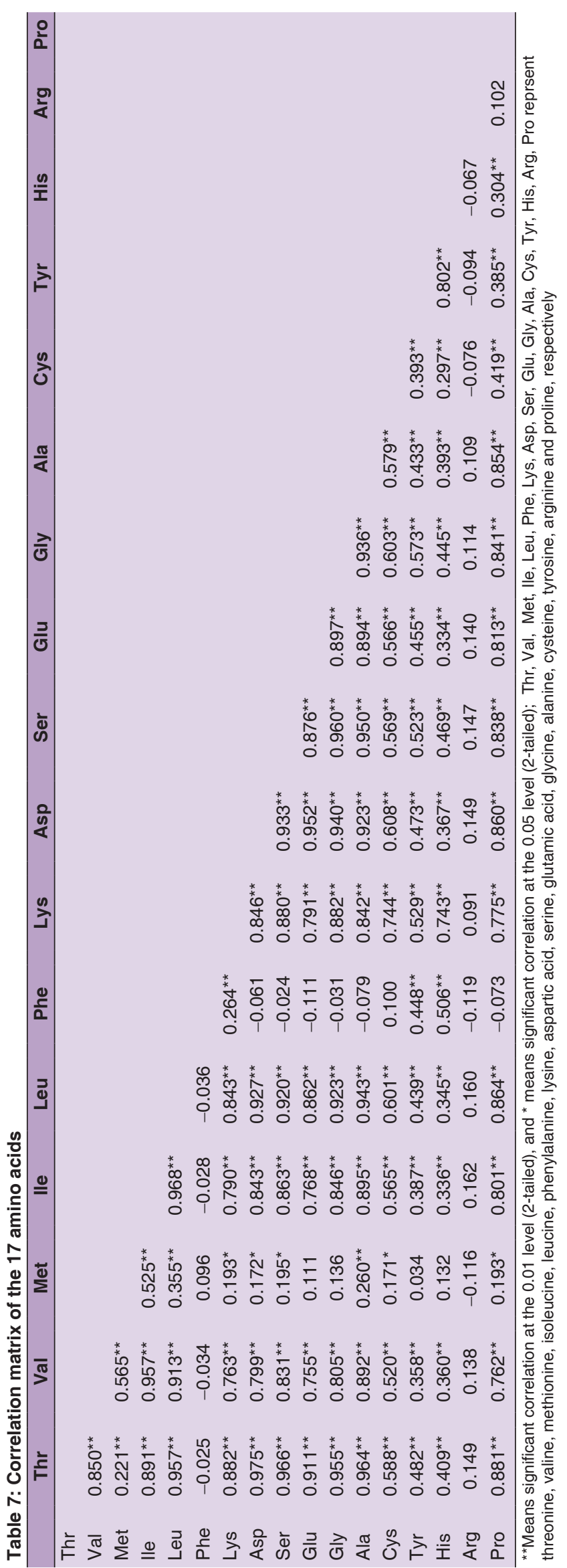




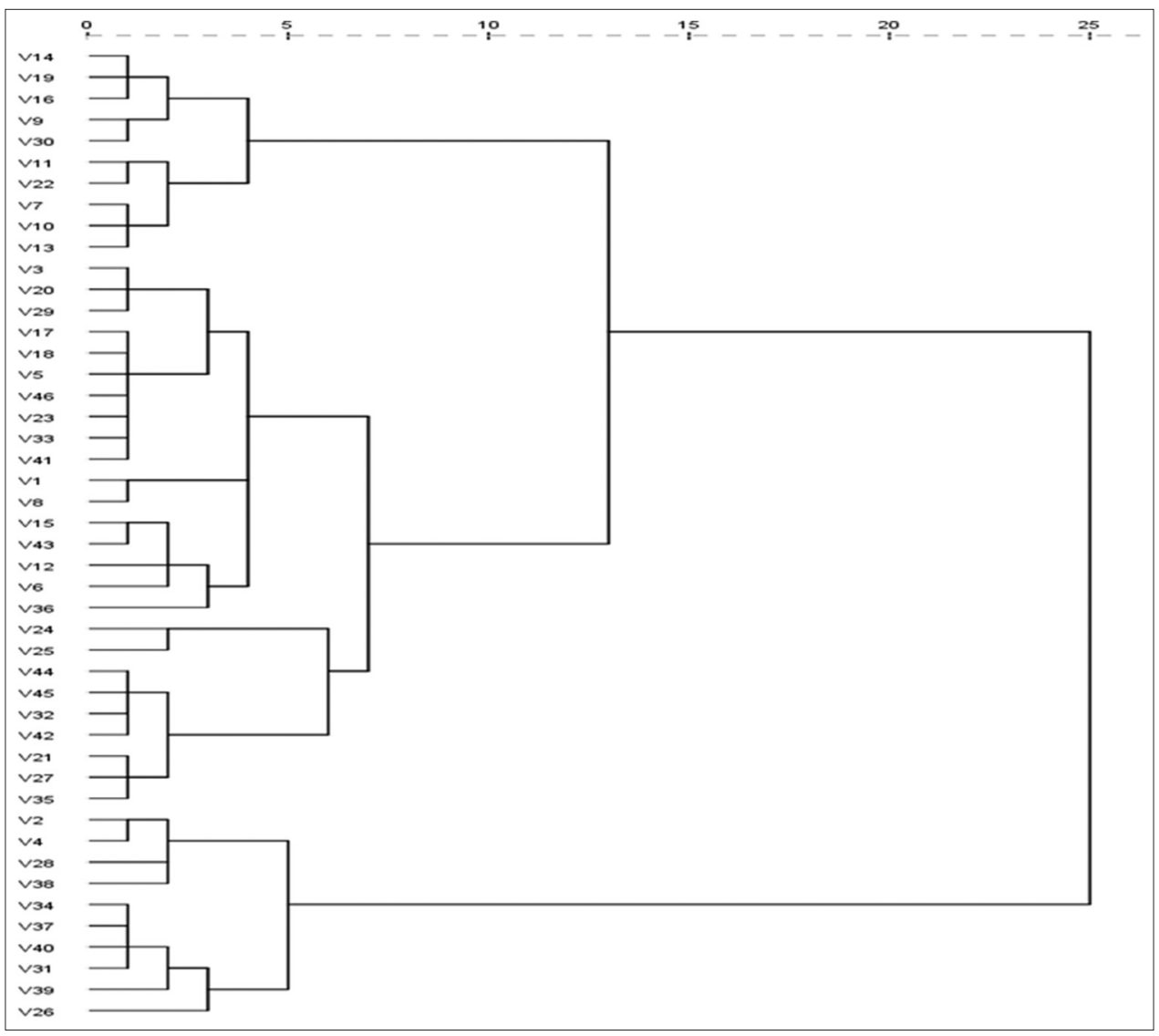

Fig 2. Cluster analysis of 46 P. lactiflora cultivars. 46 cultivars of $P$. lactiflora from V1 to V46 were same as in Fig. 1.

Table 8: Eigenvalue, contribution rate and accumulative contribution rate of quality evaluation

\begin{tabular}{lccc}
\hline Components & $\begin{array}{c}\text { Eigen } \\
\text { value }\end{array}$ & $\begin{array}{c}\text { Contribution } \\
\text { rate (\%) }\end{array}$ & $\begin{array}{c}\text { Accumulative } \\
\text { contribution rate (\%) }\end{array}$ \\
\hline PC1 & 2.547 & 19.164 & 19.164 \\
PC2 & 1.501 & 16.677 & 35.841 \\
PC3 & 1.364 & 13.664 & 49.505 \\
PC4 & 1.024 & 12.477 & 61.982 \\
PC5 & 0.982 & 10.399 & 72.381 \\
PC6 & 0.860 & 10.385 & 82.766 \\
\hline
\end{tabular}

edible quality, which were basically agreement with cultivars in the third section of principal components analysis. The category closer to the bottom of the figure aggregated other 10 cultivars, including V2, V4, V28, V38, V34, V37, V40 V31, V39 and V26, which contained higher contents of total flavonoids, total phenolics, mineral elements such as iron, zinc and amino acid, and suited for consumption. These cultivars were basically agreement with cultivars in the first section of principal components analysis. The category located in the middle of the figure gathered the remaining 26 cultivars, which were basically agreement with cultivars in the second section of principal components analysis (cultivars not listed).
Table 9: Rotated component matrix of the principle component analysis

\begin{tabular}{lcccccc}
\hline Factors & \multicolumn{7}{c}{ Principle components } \\
\cline { 2 - 7 } & PC1 & PC2 & PC3 & PC4 & PC5 & PC6 \\
\hline Protein & 0.160 & 0.838 & -0.044 & 0.119 & -0.105 & 0.051 \\
Vc & -0.056 & 0.498 & -0.721 & 0.146 & -0.064 & 0.049 \\
Fe & -0.120 & 0.561 & 0.254 & 0.563 & -0.006 & -0.126 \\
Zn & 0.204 & 0.026 & -0.101 & 0.869 & 0.068 & 0.132 \\
Total & -0.143 & 0.154 & 0.866 & 0.061 & 0.012 & -0.027 \\
flavonoids & & & & & & \\
Total & 0.068 & 0.063 & -0.045 & 0.072 & -0.044 & 0.976 \\
phenolics & & & & & & \\
$\quad$ Lys & 0.890 & 0.050 & -0.080 & 0.061 & 0.112 & -0.016 \\
$\quad$ Met & 0.070 & -0.042 & 0.046 & 0.057 & 0.980 & -0.044 \\
Tyr & 0.917 & 0.152 & -0.037 & 0.110 & -0.037 & 0.106 \\
Phe & 0.412 & 0.589 & -0.092 & -0.336 & 0.207 & 0.183 \\
\hline
\end{tabular}

\section{DISCUSSION}

Our preliminary experiment found that herbaceous peony petals at full bloom period had the best edible quality considering nutrients including soluble sugar, organic acid, protein, vitamin $\mathrm{C}$, total phenolics, total flavonoids, mineral elements and SOD activity (Unpublished data). Therefore, the nutrients in flower petals of $P$. lactiflora cultivars were 
Table 10: Principal component expression of different $\boldsymbol{P}$. lactiflora cultivars

\begin{tabular}{lc} 
Principal component & Calculation formula \\
\hline F1 & $0.57 \times Z X 1+0.56 \times Z X 2+0.10 \times Z X 3+0.26 \times Z X 4-0.09 \times Z X 5-0.04 \times Z X 6+0.13 \times Z X 7-0.08 \times Z X 8+0.04 \times Z X 9+0.04 \times Z X 10$ \\
F2 & $0.12 \times Z X 1+0.04 \times Z X 2+0.68 \times Z X 3+0.48 \times Z X 4+0.13 \times Z X 5+0.41 \times Z X 6+0.02 \times Z X 7+0.46 \times Z X 8-0.03 \times Z X 9+0.05 \times Z X 10$ \\
F3 & $-0.03 \times Z X 1-0.07 \times Z X 2-0.04 \times Z X 3-0.08 \times Z X 4+0.74 \times Z X 5-0.62 \times Z X 6-0.09 \times Z X 7+0.22 \times Z X 8+0.04 \times Z X 9-0.04 \times Z X 10$ \\
F4 & $0.11 \times Z X 1+0.06 \times Z X 2+0.12 \times Z X 3-0.33 \times Z X 4+0.06 \times Z X 5+0.14 \times Z X 6+0.86 \times Z X 7+0.56 \times Z X 8+0.06 \times Z X 9+0.07 \times Z X 10$ \\
F5 & $-0.04 \times Z X 1+0.11 \times Z X 2-0.11 \times Z X 3+0.21 \times Z X 4+0.01 \times Z X 5-0.06 Z X 6+0.07 \times Z X 7+0.01 \times Z \times 8+0.99 \times Z X 9-0.04 \times Z X 10$ \\
F6 & $0.11 \times Z X 1-0.02 \times Z X 2+0.05 \times Z X 3+0.20 \times Z X 4-0.03 Z X 5+0.05 \times Z X 6+0.14 \times Z X 7-0.14 \times Z X 8-0.05 \times Z X 9+1.05 \times Z X 10$ \\
\hline
\end{tabular}

\begin{tabular}{|c|c|c|c|c|c|}
\hline Cultivar & Score & Ranking & Cultivar & Score & Ranking \\
\hline V28 & 1.61 & 1 & V6 & -0.07 & 24 \\
\hline V4 & 1.17 & 2 & V43 & -0.07 & 25 \\
\hline V38 & 1.13 & 3 & V3 & -0.07 & 26 \\
\hline V26 & 1.02 & 4 & V20 & -0.08 & 27 \\
\hline V31 & 0.97 & 5 & V46 & -0.21 & 28 \\
\hline V2 & 0.84 & 6 & V23 & -0.23 & 29 \\
\hline V24 & 0.72 & 7 & V5 & -0.32 & 30 \\
\hline V34 & 0.62 & 8 & V33 & -0.34 & 31 \\
\hline V40 & 0.52 & 9 & V15 & -0.35 & 32 \\
\hline V12 & 0.52 & 10 & V41 & -0.47 & 33 \\
\hline V25 & 0.47 & 11 & V22 & -0.49 & 34 \\
\hline V27 & 0.47 & 12 & V11 & -0.51 & 35 \\
\hline V21 & 0.45 & 13 & V17 & -0.55 & 36 \\
\hline V35 & 0.38 & 14 & V18 & -0.60 & 37 \\
\hline V37 & 0.31 & 15 & V36 & -0.67 & 38 \\
\hline V8 & 0.23 & 16 & V30 & -0.79 & 39 \\
\hline V1 & 0.20 & 17 & V19 & -0.81 & 40 \\
\hline V39 & 0.18 & 18 & V16 & -0.83 & 41 \\
\hline V44 & 0.14 & 19 & V10 & -0.86 & 42 \\
\hline V45 & 0.11 & 20 & V14 & -0.94 & 43 \\
\hline V32 & 0.09 & 21 & V7 & -0.97 & 44 \\
\hline V42 & 0.01 & 22 & V9 & -1.00 & 45 \\
\hline V29 & -0.03 & 23 & V13 & -1.38 & 46 \\
\hline
\end{tabular}

measured at full bloom stage to screen edible cultivars. Results showed that the contents were differed between cultivars. Although variation existed in the petal color of different varities, the nutrient contents weren't directly proportional to the flower color.

The soluble sugar content was $66.55-177.28 \mathrm{mg} / \mathrm{g}$ $\mathrm{FW}$, organic acid 2.19-6.90 mg/g FW, soluble protein 6.53-121.56 mg/g FW, Vitamin C 9.77-30.24 mg/100 g FW, total phenolics $9.41-33.01 \mathrm{mg} / \mathrm{g}$ DW, total flavonoids 3.50-17.56 mg/g DW, SOD activity 305.62-520.42 U/g $\mathrm{FW}$, total amino acids $6.43-11.99 \mathrm{mg} / 100 \mathrm{~g}$ DW. Zhang et al. (2016) detected 18 kinds of amino acids in ornamental peach flowers and found that Asp and Pro were two amino acids with much higher content. From our results, we showed that the contents of Glu and Asp were much higher in herbaceous peony petals, while that of Pro was much lower (Table 6). Nunes and Carvalho (2013) found that total amino acid (T) content varied from $28-49 \mathrm{mg} / \mathrm{g}$ and essential amino acids (E) from $8-20 \mathrm{mg} / \mathrm{g}$ for flowers and leaves of Erica australis L., respectively, with different distributions within the plant, which was lower than those in herbaceous peony petals with the average level of $8.88 \mathrm{~g} / 100 \mathrm{~g}(88.8 \mathrm{mg} / \mathrm{g})$ and $3.78 \mathrm{~g} / 100 \mathrm{~g}(37.8 \mathrm{mg} / \mathrm{g})$. Furthermore, peach flowers contained higher contents of $\mathrm{Mg}, \mathrm{Ca}, \mathrm{K}$ and $\mathrm{Mn}$, which are beneficial for human health (Zhang et al., 2016). In this study, the average content of $\mathrm{Na}$, $\mathrm{Mg}, \mathrm{K}, \mathrm{Ca}, \mathrm{Mn}, \mathrm{Fe}, \mathrm{Ni}, \mathrm{Zn}, \mathrm{Mo}, \mathrm{Cr}$ were $55.88 \pm 14.90 \mu \mathrm{g} / \mathrm{g}$ DW, $1218.22 \pm 349.60 \mu \mathrm{g} / \mathrm{g}$ DW, $11252.23 \pm 2477.54 \mu \mathrm{g} / \mathrm{g}$ DW, $1975.40 \pm 706.58 \mu \mathrm{g} / \mathrm{g}$ DW, $8.30 \pm 6.55 \mu \mathrm{g} / \mathrm{g}$ DW, $103.56 \pm 182.72 \mu \mathrm{g} / \mathrm{gDW}, 10.73 \pm 37.94 \mu \mathrm{g} / \mathrm{gDW}, 22.80 \pm 16.68$ $\mu \mathrm{g} / \mathrm{g}$ DW, $1.84 \pm 5.89 \mu \mathrm{g} / \mathrm{g}$ DW and $17.36 \pm 44.89 \mu \mathrm{g} / \mathrm{g}$ DW, respectively (Table 4). $\mathrm{Mg}$, Ca and $\mathrm{K}$ contents were also higher, while Mn content was much lower.

Gao (2013) made a comprehensive assessment on biological traits, glucosinolate, carotenoids and flavor quality of Chinese cabbage with fuzzy synthetic evaluation. Yang (2014) carried out overall evaluation on several quality indexes of Hemerocallis by fuzzy mathematics membership function. Jiang (2014) comprehensively analyzed the nutritional value of apple fruit with principal component analysis. Moreover, some researchers conducted comprehensive analysis with the combined method of principal component analysis and cluster analysis (Schnackenberg, 2010; Derek, 2012; Geốcze, 2012; Gong, 2014). Jin et al. (2010) determined the nutritional quality of 20 kinds of chrysanthemum by principal component analysis, and selected 3 types of edible chrysanthemum with high nutritional quality. Yang et al. (2014) confirmed the nutritional quality of 25 varieties of sweet-scented osmanthus by principal component analysis, and selected 4 edible osmanthus varieties with high nutritional quality. This research mainly adopted the principal component analysis combined with cluster analysis to perform comprehensive evaluation, with the following four category evaluation indexes including nutritional components, bioactive ingredients, amino acids and mineral elements. The relationship analysis between quality indexes showed that soluble sugar, organic acid, protein, Vc, total phenolics, total flavonoids and SOD had no significant difference between each other. The contents of soluble sugar, organic acid and SOD showed a small difference among cultivars. Therefore, protein, Vc, total phenolics and total flavonoids were selected on behalf of 
nutritional quality and bioactive components of herbaceous peony flower. There was significant correlation between the content of $\mathrm{Mn}, \mathrm{Fe}, \mathrm{Ni}$ and that of $\mathrm{Cr}$, and the content of $\mathrm{Mg}$ and that of $\mathrm{K}, \mathrm{Ca}, \mathrm{Zn}$. However, the content of other mineral element had little difference between cultivars. $\mathrm{Fe}$ and $\mathrm{Ca}$ were selected on behalf of mineral elements. There was significant correlation between the content of Thr, Val, Ile, Leu, Lys, Asp, Ser, Glu, Gly, Ala and that of Pro, and the content of Tyr and that of His. However, the content of other amino acid had little difference between cultivars. Phe, Met, Lys and Tyr were selected on behalf of amino acids. Overall, we selected 10 components including protein, Vc, total phenolics, total flavonoids, Fe, Zn, Lys, Tyr, Met and Phe on behalf of basic nutrients, mineral elements and amino acids in herbaceous peony flower petal, and as edible quality evaluation index.

Principal component analysis of 10 kinds of nutrients in flower petals of 46 cultivars were conducted using SPSS, and six principal components were obtained. The first and the five principal component were the comprehensive index of amino acid content in peony petals. The second principal component mainly reflected the index of protein content. The third principal component was the index of Vc and total flavonoids content. The fourth principal component mainly reflected the comprehensive index of mineral element content in peony petals. the sixth principal component was the index to reflect the total phenolics content. Finally, ten cultivars with better edible quality were screened, including 'Dielian Qihua', 'Zhushapan', 'Xueyuan Honghua', 'Wulong Jisheng', 'Honglou', 'Bingshan', 'Hongyan Yushuang', 'Zituo Ronghua', 'Zifengyu' and 'Fenlou Dianchun'.

\section{ACKNOWLEDGEMENTS}

This work was financially sponsored by the Priority Academic Program Development from Jiangsu Government, 'Three New Agricultural Program of Jiangsu Province (SXGC[2017]297), Priority Academic Program Development from Jiangsu Government, Agricultural Science and Technology Support Program of Jiangsu Province (BE2012468) and Excellent Youth Backbone Teachers of Yangzhou University (2014).

\section{Authors' contribution}

C. Z. and J. T. designed this study. W. L. and H. C. wrote the article and corrected it. S. Y. and Y. H. conducted the experimental work.

\section{REFERENCES}

Ahmed, A. F., H. J. Yu, X. Y. Yang and W. J. Jiang. 2014. Deficit irrigation affects growth, yield, vitamin $\mathrm{C}$ content, and irrigation water use efficiency of hot pepper grown in soilless culture. HortScience. 49: 722-728.

Bayram, O., O. Sagdic and L. Ekici. 2015. Natural food colorants and bioactive extracts from some edible flowers. J. Appl. Bot. Food Qual. 88: 170-176.

Benvenuti, S., E. Bortolotti and R. Maggini. 2016. Antioxidant power, anthocyanin content and organoleptic performance of edible flowers. Sci. Hortic. 199: 170-177.

Chen, G. L., S. G. Chen, Y. Q. Xie, F. Chen, Y. Y. Zhao, C. X. Luo and Y. Q. Gao. 2015. Total phenolic, flavonoid and antioxidant activity of 23 edible flowers subjected to in vitro digestion. J. Funct. Foods 17: 243-259.

Cunningham, E. 2015. What nutritional contribution do edible flowers make? J. Acad. Nutr. Diet. 115: 856.

Derek, F., J. V. Keenan, G. Ronan, F. Butler and N. P. Brunton. 2012. Selecting apple cultivars for use in ready-to-eat desserts based on multivariate analyses of physico-chemical properties. LWT-Food Sci. Technol. 48: 308-315.

Du, Y., J. H. Sheng, X. S. Cui, Z. X. Zhai, X. H. Dong and Y. H. Guo. 2012. Determination of the content of mineral elements in Cistanche tubulosa from different areas. Spectrosc. Spect. Anal. 32: 2824-2827.

Feng, L. G., Y. M. Li, L. X. Sheng, T. L. Li, D. Q. Zhao and J. Tao. 2016. Comparative analysis of headspace volatiles of different herbaceous peony (Paeonia lactiflora Pall.) Cultivars. J. Essent. Oil Bear. Plants. 19: 167-175.

Gao, F. 2013. Comparative Study on Biological Traits and Quality of Different Chinese Cabbage Cultivars. Master Thesis, Zhejiang Agriculture and Forestry University, China (In Chinese with English abstract).

Geőcze , K. C., L. C. Barbosa, P. H. Fidêncio, F. O. Silvério, C. F. Lima, M. C. A. Barbosa and F. M. D. Ismail. 2013. Essential oils from pequi fruits from the Brazilian Cerrado ecosystem. Food Res. Int. 54: 1-8.

Gong, L. Y., X. J. Meng, N. Q. Liu and J. F. Bi. 2014. Evaluation of apple quality based on principal component and hierarchical cluster analysis. J. Chin. Agric. Eng. 13: 276-285.

Grzeszczuk, M., A. Stefaniak and A. Pachlowska. 2016. Biological value of various edible flower species. Acta Sci. Pol. Hortic. 15: 109-119.

He, J., T. Yin, Y. Chen, L. Cai, Z. Tai, Z. Li, C. Liu, Y. Wang and Z. Ding. 2015. Phenolic compounds and antioxidant activities of edible flowers of Pyrus pashia. J. Funct. Foods. 17: 371-379.

Hou, X. J., Y. L. Zhu and X. J. Hou. 2012. Effects of root of herbaceous peony on lipid metabolism of rheumatoid arthritis patients. Heart. 98(S2): E289-E289.

Huang, D. J., B. X. Ou and R. L. Prior. 2005. The chemistry behind antioxidant capacity assays. J. Agric. Food Chem. 53: 1841-1856.

Jia, N., Q. Y. Shu, L. S. D. Wang, Y. J. Xu and Z. A. Liu. 2008. Analysis of petal anthocyanins to investigate coloration mechanism in herbaceous peony cultivars. Sci. Hortic. 17(2): 167-173.

Jiang, H. 2014. The Chemical Components Analysis and Preliminary Quality Evaluation of Yantai Apple. Master Thesis, Yantai University.

Jin, Y. S., Y. H. Xuan, Y. Z. Jin, M. L. Chen and J. Tao. 2013. Biological activities of herbaceous peony flower extracts. Asian J. Chem. 25: 3835-3838.

Jin, X. X., F. D. Chen, S. M. Chen and W. M. Fang. 2010. Nutrition in 20 cultivars of chrysanthemum. J. Zhejiang Forestry Coll. 27(1): 22-29.

Koike, A., J. C. M. Barreira, L. Barros, S. B. Celestino, 
A. L. C. Villavicencio and I. C. F. Ferreira. 2015. Edible flowers of Viola tricolor L. As a new functional food: Antioxidant activity, individual phenolics and effects of gamma and electron-beam irradiation. Food Chem. 179: 6-14.

Liu, P. and M. J. Li. 2007. Experimental Techniques of Plant Physiology, Science Publishing Company, Beijing, China.

Liu, P., X. Q. Shao, Y. F. Ding, X. D. Liu, T. L. Wang and X. R. Wang. 2014. Comparison of nutrient contents in petals of different herbaceous peony cultivars. North. Hortic. 1: 151-153.

Loizzo, M. R., A. Pugliese, M. Bonesi, M. C. Tenuta, F. Menichini, J. Xiao and R. Tundis. 2016. Edible flowers: A rich source of phytochemicals with antioxidant and hypoglycemic properties. J. Agric. Food Chem. 64: 2467-2474.

Lu, B., M. Li and R. Yin. 2016. Phytochemical content, health benefits, and toxicology of common edible flowers: A review (2000-2015). Crit. Rev. Food Sci. Nutr. 56: S130-S148.

Matthaus, B. and M. M. Ozcan. 2011. Chemical evaluation of flower bud and oils of tumbleweed (Gundelia tourneforti L.) As a new potential nutrition sources. J. Food Biochem. 35: 1257-1266.

Mlcek, J. and O. Rop. 2011. Fresh edible flowers of ornamental plants - A new source of nutraceutical foods. Trends Food Sci. Technol. 22: 561-569.

Ning, C. L., Y. Jiang, J. S. Meng, C. H. Zhou and J. Tao. 2015. Herbaceous peony seed oil: A rich source of unsaturated fatty acids and gamma-tocopherol. Eur. J. Lipid Sci. Technol. 117: 532-542.

Nunes, R. and I. S. Carvalho. 2013. Antioxidant activities, distribution of phenolics and free amino acids of Erica australis L. Leaves and flowers collected in Algarve, Portugal. Nat. Prod. Res. 27: 1664-1667.

Qureshi, M. N., G. Stecher and G. K. Bonn. 2014. Quality control of herbs: Determination of amino acids in Althaea officinalis, Matricaria chamomilla and Taraxacum officinale. Pak. J. Pharm. Sci. 27: 459-462.

Rop, O., J. Mlcek, T. Jurikova, J. Neugebauerova and J. Vabkova. 2012. Edible flowers-a new promising source of mineral elements in human nutrition. Molecules. 17: 6672-6683.

Schnackenberg, B. J., U. T. Saini, B. L. Robinson, S. F. Ali and T. A. Patterson. 2010. An acute dose of gamma-hydroxybutyric acid alters gene expression in multiple mouse brain region. Neuroscience. 170: 523-541.

Shi, J., J. Gong, J. Liu, X. Wu and Y. Zhang. 2009. Antioxidant capacity of extract from edible flowers of Prunus mume in China and its active components. LWT-Food Sci. Technol. 42: 477-482.
Sotelo, A., S. Lopez-Garcia and F. Basurto-Pena. 2007. Content of nutrient and anti-nutrient in edible flowers of wild plants in Mexico. Plant Foods Hum. Nutr. 62(3): 133-138.

Tundis, R., M. Marrelli, F. Conforti, M. C. Tenuta, M. Bonesi, F. Menichini and M. Loizzo. 2015. Trifolium pratense and T. repens (Leguminosae): Edible flower extracts as functional ingredients. Foods. 4(3): 338-348.

Wu, Y. Q., M. R. Wei, D. Q. Zhao and J. Tao. 2016. Flavonoid content and expression analysis of flavonoid biosynthetic genes in herbaceous peony (Paeonia lactiflora Pall.) With double colors. J. Integr. Agric. 15: 2023-2031.

Xiong, L., J. Yang, Y. Jiang, B. Lu, Y. Hu, F. Zhou, S. Mao and C. Shen. 2014. Phenolic compounds and antioxidant capacities of 10 common edible flowers from China. J. Food Sci. 79: C517-C525.

Yang, L. 2014. Nutritional Component Analysis and Quality Evaluation of Hemerocallis Plants. Master Thesis, Jilin Agriculture University, China.

Yang, X. L., F. Zhao and L. G. Wang. 2014. Analysis of nutrients in the petals of 25 cultivars of Osmanthus fragrans. J. Fujian Coll. Forestry. 34(1): 5-10.

Yang, Z., J. Zhang and Z. X. Tang. 2011. Selection of indexes for evaluating fruit table quality on wine grape in Xinjiang. Guangdong Agric. Sci. (6): 119-123.

Yu, N. 2011. The Senescence Physiology and Regulation of Herbaceous Peony and Analysis of Nutrition and Health Components in Petals of Main Varities of Poeny. Master Thesis, Henan Normal University.

Zhang, H. X., Y. K. Rui, H. Liu and Y. H. Xie. 2016. Determination of amino acids and mineral elements in flower tissue of Amygdalus persica var. Persica f. Duplex. Indian J. Hortic. 73(2): 294-295.

Zhao, D. Q., Y. Jiang, C. L. Ning, J. S. Meng, S. S. Lin, W. Ding and J. Tao. 2014. Transcriptome sequencing of a chimaera reveals coordinated expression of anthocyanin biosynthetic genes mediating yellow formation in herbaceous peony (Paeonia lactiflora Pall.). BMC Genomics. 15: 689.

Zhao, D. Q., M. R. Wei, D. Liu and J. Tao. 2016. Anatomical and biochemical analysis reveal the role of anthocyanin's in flower coloration of herbaceous peony. Plant Physiol. Biochem. 102: 97-106.

Zhou, C. H., Y. Zhang, Y. L. Sheng, D. Q. Zhao, S. S. Lv, Y. Hu and J. Tao. 2011. Herbaceous Peony (Paeonia lactiflora Pall.) As an alternative source of oleanolic and ursolic acids. Int. J. Mol. Sci. 12: 655-667. 